\title{
Las formas breves de la narrativa folklórica en la comarca de Valdejalón (Zaragoza)
}

\author{
Carlos González Sanz \\ Instituto Aragonés de Antropología, Zaragoza \\ bozalongo@hotmail.com
}

\begin{abstract}
RESUMEN
Recientemente se ha editado la obra Músicas y palabras en Valdejalón, en la que se analizan los resultados de la amplia recopilación de folklore realizada en esta comarca aragonesa en años previos por Carolina Ibor Monesma y en la que colaboré tanto en la recopilación de textos procedentes de Urrea de Jalón como, principalmente, en el estudio y la catalogación de los relatos folklóricos recogidos en estas tierras, cercanas a la capital zaragozana. Entre ellos destaca el amplio repertorio de relatos breves de carácter jocoso, fundamentalmente cuentecillos de carácter obsceno o escatológico y cuentos de cazadores. En el presente trabajo se da cuenta de las dificultades encontradas para catalogar estos relatos, que a menudo no se corresponden con ninguno de los tipos establecidos en ATU. No obstante, se apuntan las analogías que presentan con relatos semejantes de otros territorios peninsulares.
\end{abstract}

PALABRAS CLAVE

cuento, ATU, Valdejalón, obsceno, cazador 


\title{
RESUM
}

Recentment ha estat editada l'obra Músicas y palabras en Valdejalón, en la qual s'analitzen els resultats de l'àmplia recopilació de folklore realitzada en aquesta comarca aragonesa en anys previs per Carolina Ibor Monesma, en la qual vaig col.laborar tant en la recopilació de textos procedents d'Urrea de Jalón com, principalment, en l'estudi i catalogació dels relats folklòrics recollits en aquestes terres, properes a la capital saragossana. Entre ells destaca l'ampli repertori de relats breus de caràcter jocós, fonamentalment rondalles de caràcter obscè o escatològic i rondalles de caçadors. En aquest treball es dóna compte de les grans dificultats trobades per a catalogar aquests relats, que sovint no es corresponen amb cap dels tipus establerts a ATU, assenyalant, però, les analogies que presenten amb relats semblants d'altres territoris peninsulars.

\section{PARAules ClaU}

rondalla, ATU, Valdejalón, obscè, caçador

\begin{abstract}
This year has seen the publication of Músicas y palabras en Valdejalón (Music and Words in Valdejalon), a study which analyzes the results of the wide-ranging compilation of folklore carried out in recent years in this Aragonese region by Carolina Ibor Monesma and in which I collaborated both in the compilation of texts from Urrea de Jalon and in the study and cataloguing of the folktales collected in these areas close to the city of Saragossa. Of particular note is the wide repertoire of humorous short stories that are essentially obscene or scatological in nature and the tales of hunters. This paper describes the significant difficulties that we encountered when trying to catalogue these stories, which often do not correspond to any of the types established in the ATU, whilst also highlighting analogies between these tales and similar stories from other Iberian territories.
\end{abstract}

KEYWORDS

folktale, ATU, Valdejalón, obscene, hunter 


\section{Introducción}

Recientemente se ha publicado la obra Músicas y palabras en Valdejalón, en la que se analizan los resultados de la amplia recopilación de folklore realizada en años previos en esta comarca aragonesa por Carolina Ibor Monesma, y en la que se contextualizan los diversos testimonios recogidos, que, por otra parte, pasarán en breve a dar forma a un archivo sonoro en el que se podrán consultar todos los fonogramas obtenidos en esta investigación (Ibor 20I2). En el verano de 2005 tuve la oportunidad de colaborar con su autora realizando una pequeña parte del trabajo de campo llevado a cabo en las localidades zaragozanas de Urrea y Plasencia de Jalón; con posterioridad, también participé en la redacción de la obra citada, analizando y contextualizando los relatos de diversa tipología recogidos en esta campaña (González 2oI2: 249-275).

A continuación ofreceré un somero análisis de los resultados obtenidos en ella, centrándome en exclusiva en los relatos breves que, estructuralmente, se corresponden con el tipo de narración denominada en alemán Schwank — fundamentalmente, pues, en los cuentecillos jocosos-, para pasar a ofrecer después algunos ejemplos concretos que ponen de manifiesto las dificultades de clasificación de este tipo de relatos a partir de los catálogos existentes.

\section{Cuentos, chistes, anécdotas...: sobre las formas breves de la narra- ción folklórica en la comarca de Valdejalón}

Decía Maxime Chevalier, en un estudio dedicado precisamente a los chascarrillos aragoneses:

en una época en la cual aprecio tan exclusivo se hace de los cuentos maravillosos [...] sería un absurdo despreciar los cuentos jocosos. Por el motivo muy sencillo de que los cuentos maravillosos son largos y complejos, y exigen, y siempre han exigido, narradores especializados. En cambio un hombre cualquiera puede referir un cuento chistoso, y lo mismo puede - milagroso poder de la palabra - evocar en una frase proverbial un cuento chistoso. Los cuentos maravillosos tienen eminente valor poético y encierran una riqueza imaginativa insuperable; pero los cuentos que forman el fondo del folklore activo, el que circula en el habla coloquial, son los cuentos jocosos - verdad elemental que alguna vez se pierde de vista (Chevalier 2000: I5).

Las palabras del maestro nos ponen sobre la pista de tres asuntos de importancia a la hora de valorar los resultados obtenidos en el trabajo al que nos hemos referido, a saber: a) la riqueza y vigencia de los relatos jocosos y chistes, que quedó demostrada en la citada investigación por el escaso número de informantes capaces de narrar con solvencia un cuento maravilloso frente al relativo gran número de anécdotas, chistes y cuentecillos jocosos recopilados; $b$ ) el prestigio que tienen determinados géneros o formas de expresión frente a otras, lo que en este caso se puso de manifiesto por la estrecha vinculación, desde hace siglos, de la comarca de Valdejalón con la cercana ciudad de Zaragoza, lo que, junto con el fuerte crecimiento experimentado en estos últimos años, ha producido una notable decadencia del folklore tradicional y una preferencia de los informantes por los 
relatos relacionados con la denominada literatura baturrista y, muy especialmente, por los textos en verso - proporcionalmente, el número de romances y otras composiciones poéticas superó con creces al de las narraciones en prosa, incluso a los chistes-; ${ }^{\mathrm{I}} \mathrm{c}$ ) las diversas denominaciones que se dan a los relatos breves de carácter humorístico, lo que supone una dificultad añadida —como ejemplo, valga señalar que pudimos comprobar que el término chiste era el preferido en la mayoría de los casos, aunque con él se referían no solo a los cuentecillos jocosos, sino a cualquier texto de carácter humorístico, como las adivinanzas con doble sentido de carácter obsceno-.

Empezando por este último asunto, conviene delimitar previamente nuestro objeto de estudio, para lo cual creo que, junto con la etnopoética, uno de los estudios más esclarecedores es el llevado a cabo por Rosa Alicia Ramos, que diferencia, en el campo de los relatos folklóricos de carácter ficticio —en los que sitúa al cuento-, dos órdenes básicos en relación con su estructura: los cuentos más complejos, formados por sucesivos episodios, para los que considera adecuado el uso del término alemán Märchen, y los cuentecillos de carácter jocoso, mucho más sencillos y monoepisódicos —o a lo sumo compuestos por la reiteración en paralelo de un episodio básico-, perfectamente semejantes, pues, al Schwank alemán (Ramos I988: I3-4I). Estos últimos, según Ramos, no precisan de fórmula final en la medida en que el conflicto entre los personajes se resuelve siempre humorísticamente, dejando clara la risa al fin del discurso ficticio - lo que no sucede en el Märchen, que sí precisa de una fórmula de cierre que delimite el final del discurso sin valor de verdad-.

Es obvio que, en el campo del Schwank, nos encontraríamos con el amplísimo repertorio de cuentecillos jocosos del Índice internacional del cuento tipo (Uther 2004), pero también se incluirían en él, por su semejanza estructural, los cuentos de animales, algunos de los cuentos religiosos y novelescos —en especial los que tienen como motivo central una respuesta o solución ingeniosa a una dura prueba- y la gran mayoría de los cuentos del ogro estúpido — que, frecuentemente, como es sabido, son versiones de los cuentos de animales con personajes humanos-.

Por otra parte, Ramos considera que los cuentecillos jocosos se pueden diferenciar de los chistes por presentar cierto desarrollo argumental —en todo caso mayor que en el chiste- y por el hecho de que en ellos se produce un intento de caracterizar a los personajes por contraste, de lo que resulta el efecto humorístico por la confrontación entre la lógica razonable de uno de los personajes y la lógica absurda de su antagonista, que lo lleva a la degradación o a la no realización de sus metas a causa de su insensatez. Por el contrario, en los chistes, en los que

I. En relación con la llamada literatura baturrista, que sin duda ha influido en el folklore en esta y muchas otras comarcas aragonesas, conviene recordar el hecho de que este tipo de literatura, variante local y un tanto burda del costumbrismo, fue desarrollada sobre todo por la burguesía zaragozana, que, si bien utilizó en ocasiones los temas del cuento folklórico como materia para sus relatos, llevó a cabo al mismo tiempo una ridiculización del prototipo del campesino aragonés, el baturro, que, por desgracia y, como es bien sabido, fue luego asumida por algunos como seña de identidad de lo aragonés. Jesús Rubio (I99I) ha señalado, en relación con la colección «La novela de viaje aragonesa», la vinculación de parte de los autores de esta con el régimen franquista, lo que explicaría también la influencia de este tipo de literatura en una comarca que, como se ha dicho, mantenía una relación muy estrecha con la capital. 
únicamente se plantea una situación aislada sin incidentes previos ni posteriores, la simple locución del personaje basta para evidenciar sus limitaciones, produciéndose en ellos el contraste, y el consiguiente efecto humorístico entre dicho personaje, incapaz de percibir lo absurdo de su lógica, y el propio auditorio, que experimenta una sensación de superioridad intelectual con respecto al protagonista del chiste, acentuada por el hecho de percibir la insensatez de este sin la ayuda del narrador (Ramos I988: 29).

Establecidos estos límites, y aunque los narradores no tengan por qué ser conscientes de estas diferencias de género, conviene hacer una breve contextualización de los relatos a los que me referiré con posterioridad. Para ello puede partirse del testimonio que nos ofreció uno de nuestros informantes, Jesús Labella, de Urrea de Jalón (Zaragoza), quien recordaba con añoranza las frecuentes trasnochadas que, en su infancia, allá por los años treinta del pasado siglo, reunían en alguna casa a familia y vecinos, incluidos los más pequeños, para llevar a cabo tareas colectivas como el despinochado del maíz, siendo este el momento en que con más frecuencia se contaban todo tipo de historias. Estas mismas trasnochadas, por lo que nos contaron en otros lugares, se celebraban también en algunas ocasiones con el fin de buscar un rato de diversión y conversación; era entonces cuando el humor más escatológico y obsceno se hacía especialmente presente. Según testimonio del mismo Jesús Labella, las reuniones que se daban en las bodegas para la elaboración del vino eran también momentos en los que, en medio de un ambiente festivo, se contaban relatos humorísticos, adivinanzas o anécdotas, además de otras composiciones musicales, como jotas o cantos de bodega.

En todo caso, volviendo a la conexión establecida entre la labor de limpiar de su camisa de paja las mazorcas de maíz y la actividad de narrar que la acompañaba —algo que he podido observar ya en otras comarcas (González I996)—, esta costumbre pone de manifiesto de manera especialmente elocuente varias de las funciones básicas de la narrativa folklórica, a saber: a) el acompasamiento de este tipo de labores monótonas y minuciosas —o lo que viene a ser lo mismo: el entretenimiento-; b) la construcción del espacio social, con el intercambio de «críticas», anécdotas, etc., que sin duda servirían igualmente para descargar las tensiones de la dura vida en el campo en tiempos pasados y c) el hecho de que la narración sea la primera escuela de la lengua, del arte narrativo y de una sabiduría basada en la agudeza y el ingenio, esto es, en la depuración del pensamiento para saber llegar a la esencia, como en el caso de las mazorcas, al grano.

Esto último resulta muy evidente, por ejemplo, en uno de los relatos que contó, igualmente, Jesús Labella, el «Chiste de los pastores», que, por cierto, resulta de difícil catalogación, aunque tenga algunas semejanzas en su planteamiento con el tipo ATU 92I, The King and the Farmer Son. Bien visto, se diría incluso que se trata, en realidad, de un auténtico problema matemático, con el que, seguramente, los mayores trataban de despertar la habilidad para el cálculo mental de los más pequeños, al tiempo que mostraban, como suele ocurrir con algunas versiones de este relato, la superioridad intelectual — basada en la agudeza y la experiencia-de los hombres del campo con respecto a los poderosos o los habitantes de la ciudad:

Esto eran unos pastores que había aquí en el pueblo, en Urrea, y claro, había rebañicos muy pequeños y se juntan un día en el monte y le dice el uno al otro: 
-Oye, eh... Celestino, ¿por qué no me das tú una ovejica de esas que tienes en tu rebaño y tendré yo doble que tú? Y así, pues fíjate, ya puedo lucir yo de rebaño.

Y el otro le dice:

-Oye, Antonio —el uno se llamaba Celestino y el otro Antonio-. Antonio, pues, ¿por qué no me la das tú a mí y tendremos los dos iguales?

¿Cuántas tenía cada uno?

Éste era un chiste también que se las traía, ¡eh!, pa los tiempos aquellos [ríe]. ${ }^{2}$

En este perfecto ejemplo de cuento con una evidente función didáctica puede observase, además, una de las propiedades de la narración que Walter Benjamin señala en su conocido artículo sobre el narrador, como es el hecho de que el cuento reclama ser aprendido por su receptor o, lo que es lo mismo, que quien ha sido oyente de un cuento siente luego la responsabilidad de convertirse en su narrador, perpetuando así su transmisión de generación en generación (Benjamin I973: 3I8).

Quizá esto mismo explique también la posibilidad de la aplicación del cuento en situaciones reales, algo que puede observarse en una curiosa anécdota que, según noticia del mismo Jesús Labella, se produjo en el dance de Urrea de Jalón - celebrado en la festividad de San Sebastián-. En ella un vecino de la cercana localidad de Rueda de Jalón, interviniendo como espontáneo en el momento de los dichos al santo - acto que corresponde en exclusiva a los danzantes-, actuó de manera idéntica a la del personaje de un conocido cuentecillo jocoso del folklore hispánico, no incluido en ATU, pero que se corresponde perfectamente con el tipo I829*D del catálogo de Stanley L. Robe (I973) y del que, en particular en Aragón, existen numerosas versiones, de entre las cuales resulta muy conocida la que refiere Rafael Andolz (I992: III), aplicada en este caso a la Virgen de Escagüés, a la que un tallista se dirigió de la siguiente manera: «Virgen Santa de Escagüés / naixida en un fraxinal / d'o pesebre a mía burra, / tú yes hermana carnal»:

[...] vino uno de Rueda, jandanda! Se puso ahí en la entrada y dice: «Tú cerecero fuistes / de tus cerezas comí / los milagros que hagas tú / me los pongo yo aquí». El caballo que tenía preparao lo salvó, si no... le pegan un palizón que lo matan [Entrevistador: ¿Eso se lo dijo al santo?] Ese tipo de Rueda, ¡era atrevido, eh! [ríe] Se puso en la entrada mía y el caballico preparao y dos o tres amigos más. Y al oír las palabras nos revolvimos todos, que estaba señalando, que el santo se ponía ahí, aquí en esta fachada mía y en la de mi sobrino [se está refiriendo a la plaza], ahí en eso se ponía el entablao; se ponía, por lo tanto, el santo, San Sebastián, atao en el madero con las flechas. Conque... [ríe y no se llega a entender lo que dice entre dientes] y después le prepararon una, ¡tremenda!

Para finalizar con esta breve contextualización, quiero destacar además la gran importancia que adquiere en la narración folklórica la función fática, tal como defiende la investigadora Fulvia Caruso en su tesis doctoral inédita Stili ed estetica

2. Este texto y los que se citan a continuación son transcripción literal de la entrevista realizada a Jesús Labella Martínez (nacido en Urrea de Jalón el 3 de enero de i925) por Carlos González Sanz el 9 de agosto de 2005. 
della narrazione fiabistica in una comunità aragonese (I997-I998). El propio Benjamin, en el mismo artículo al que hacía referencia — en este caso confrontando la narración oral a la lectura de una novela-, afirma que «Quien escucha una historia está en contacto con su narrador: incluso quien la lee participa de esa compañía» (Benjamin I973: 32I). Pues bien, del mismo modo, confirmando lo dicho, Jesús Labella, al recordar una vez más las trasnochadas a las que antes me refería, añoraba especialmente el calor humano y la unión entre diversas generaciones de una misma familia que en ellas se daba:

¿Sabes el calor que hacía y el cariño que había en esas reuniones, que mayormente nos reuníamos padres, hijos, abuelos, primos, tíos y tías y tíos...? Ahora ya, ya cada uno va por su senda. Se está apartando de todo en la vida. Se está, como si dijéramos, en un punto de convergencia y divergencia, que en un punto se junta y en otro se separa y no se ajunta nunca. Pues eso estamos viviendo. Salimos del punto de convergencia y empieza la línea de divergencia, se va alejando y adiós. Ya se pierde la familia, se pierde todo. Entonces se unían las familias. Hala, deseando que llegara la hora esa. Y otras veces, pues, decía: «pues mira, hoy he traído poco aceite pal candil, ¡eh!». Y enseguida traían un pomico con aceite los vecinos o los familiares más cercanos. Y se pasaba la noche así.

Pasando ya al análisis de los resultados obtenidos y limitándome, como queda dicho, a los relatos breves de carácter chistoso, enumeraré a continuación los testimonios recogidos — de prácticamente todos los apartados del Índice internacional del cuento tipo-, para pasar luego a estudiar en profundidad un par de casos, que, como decía antes, ponen de manifiesto los problemas de clasificación, que, someramente, se apuntan también en el siguiente listado:

- Una versión del conocidísimo «Cuento de la zorra y el cuervo», que, como suele ser habitual, aparece contextualizado en la comarca — es una versión de ATU 57 Raven with Cheese in His Mouth recogida en Morata de Jalón-.

- Un relato acerca de un gallo y unos patos, en el que se imitan las voces características de estos animales, recogido en Ricla, y que podría considerarse una variante de ATU $236^{*}$ Miscellaneous Tales with Imitation of Bird Sounds.

- Un par de chascarrillos, procedentes de Calatorao y Morata de Jalón, respectivamente, que tienen como protagonista a un loro. El primero, en el que se juega con los malentendidos creados por este animal «parlante», es una variante de ATU 237 The Talking Parrot. El segundo, un chiste con connotaciones licenciosas y anticlericales, muy conocido en nuestra tradición, cuenta cómo, para identificar a un macho de loro, hay que arrancarle un puñado de plumas de su cabeza mientras se aparea, resultando al final que el loro así marcado se burla de un sacerdote al que ve pasar por la calle, creyendo que le han hecho la tonsura con igual fin (no aparece en los catálogos consultados, aunque resulta posible considerarlo una va- 
riante de ATU 237 The Talking Parrot, o quizá, mejor aún, de Camarena y Chevalier (I995-2003) [237A] [El loro en el retrete]). ${ }^{3}$

- $\quad$ El «Cuento del zapito», que se empeña en vivir en el charco creado en la rodada de un camino - recogido en Ricla, es una versión de ATU 278A The Frog Persists in Living in Puddle on Road-.

- $\quad$ Una versión de ATU 503 The Gifts of the Little People, contada de manera expositiva, procedente de Ricla, titulada «Cuento de un niño jiboso», que resulta muy semejante a las versiones europeas del tipo, en las que, a diferencia de las procedentes de la península ibérica, que tienen como donantes mágicos a las brujas, aparece un duende en este mismo papel, lo que podría indicar una reciente difusión como chiste de este tipo en su versión centroeuropea.

- $\quad$ El «Chiste de los pastores», que antes transcribía, y que podría ser considerado quizá como una variante de ATU 92I, The King and the Farmer Son.

- Un «Cuento de Quevedo», reportado en Almonacid de la Sierra, y que, aunque no está registrado en ninguno de los catálogos consultados, podría considerarse también una variante de ATU 92I, al tener como motivo central una respuesta ingeniosa y desconcertante - en todo caso, confirma la pervivencia de los cuentos y chistes que tienen como protagonista a Quevedo, convertido por el pueblo en prototipo por antonomasia del héroe que siempre sale triunfante gracias a sus respuestas ingeniosas-.

- Una anécdota atribuida en Ricla al tío Batecamas, y que, aunque parece tratarse de un hecho real, coincide con el argumento de ATU I296B Doves in the Setter.

- $\quad$ Un chiste sobre un cura y su casera, procedente de Morata de Jalón, versión de ATU I355B «I Can See the Whole World!», en el que las palabras del cura, referidas a la belleza de la mujer desnuda, se interpretan por un tercer personaje con resultados cómicos.

- Un chiste procedente de La Almunia de Doña Godina, que resulta ser una versión de ATU 1354 Death for the Old Couple.

- Una versión, procedente de La Almunia de Doña Godina, del tipo definido por Haboucha (I973) como ** I358D —un relato en el que el marido, un auténtico majadero, interpreta de manera equivocada la presencia del amante en el lecho-.

- $\quad$ Tres versiones del cuento de la mujer, aparentemente frugal, que comía a espaldas de su marido -ATU I373A Wife Eats So Little-, procedentes de Santa Cruz de Grío y Lumpiaque.

- Una versión de ATU i380 The Faithless Wife, procedente de Santa Cruz de Grío, en el que una mujer ruega para que su marido se vuelva ciego.

\footnotetext{
3. Como se puede comprobar, los dos últimos relatos son considerados «cuentos de animales» solo por el hecho de que su protagonista es un loro, animal que, por otra parte, a diferencia de los «animales parlantes» de la fábula, habla realmente - aunque, por supuesto, sin tener conciencia de lo que dice- - Por ello, parecería más lógico considerarlos, como de hecho hacen los informantes al denominarlos «chascarrillos», como cuentos jocosos.
} 
- Un «chiste sobre un cura», procedente de Ricla, que podría considerarse una variante de ATU I4I9 The Returning Husband Hoodwinked, no muy bien recordada y en la que la mujer consigue convencer a su pareja de que no le ha sido infiel.

- $\quad$ Dos versiones, procedentes de Ricla y de Almonacid de la Sierra, del tipo propuesto por Boggs (I930) como *I424, en el que la mujer, haciendo ver que defiende al marido ante el cura, lo declara como un auténtico cornudo sin que él se aperciba en absoluto de ello.

- Un relato conocido como «El robo de la custodia», procedente de Morata de Jalón, que podría considerarse una versión del tipo ATU I55 I* How Much the Donkey Cost, y en el que —como suele suceder en las versiones hispánicas de ATU I83i The Clergyman and Sexton at Mass- se parodia la salmodia en latín durante la misa.

- $\quad$ Dos versiones de ATU i6rz Playing Cards are My Calendar and Prayer Book —una de ellas muy fragmentaria - procedentes de La Almunia de Doña Godina, que analizaré posteriormente por su gran interés.

- Dos relatos, procedentes de Morata de Jalón y La Almunia de Doña Godina, que refieren en tono chistoso trucos utilizados por los gitanos para librarse de la justicia y que, por tanto, serían variantes de ATU I634* Various Tricks Played by Gypsies.

- Una anécdota sobre el robo de unas peras, contada en Morata de Jalón, difícil de catalogar, pero que presenta semejanzas con los motivos de los tipos ATU I676C Voices from the Graveyard, ATU I740B Thieves as Ghost y ATU 1654 The Robbers in the Death Chamber.

- Un complejo relato, procedente de Salillas de Jalón, en el que se ridiculiza a los gitanos por no conocer la liturgia e interpretarla de manera disparatada - se trataría, por tanto, de una versión de ATU I678** First Time in Church, precedida de un chiste que podría relacionarse también con ATU I634* y del motivo característico de ATU I806A* The Clergyman as Prosecutor-.

- Un chiste procedente de La Almunia de Doña Godina, que trata de un hombre que nunca había estado con una mujer y que, por ello, podría tomarse como una variante de ATU I686 The Wedding Night.

- Una versión de ATU i69i The Hungry Clergyman, muy popular y conocida en gran parte de Aragón como «Los dos hermanos y las farinetas».

- Una versión del «Cuento de los cinco sordos», procedente de La Almunia de Doña Godina — que combina elementos de ATU I698J The Misunderstood Greeting, ATU I698G Misunderstood Words Lead to Comic Results y Boggs (I930) I698*N-.

- Un chiste, contado también en La Almunia, sobre una abuela presuntamente sorda — sería, por tanto, versión de ATU I698N Pretended Deafness-.

- Un chiste procedente de La Almunia de Doña Godina en el que se ridiculiza la figura del borracho y que, por tanto, podría tomarse como variante de ATU I706 Anecdotes about Drunkards. 
- Una versión muy fragmentaria y resumida, procedente de La Almunia de Doña Godina, del cuento de «La vaca vacona»-ATU I735A The Wrong Song-, en el que un niño cambia, con resultados desastrosos para el cura, la canción que este quería que cantase en misa para denunciar el robo de su vaca.

- Una versión de un cuentecillo aplicado al cura de Berbedel, procedente de Salillas de Jalón, que se corresponde con ATU I74I The Priest's Guest and the Eaten Chickens.

- $\quad$ El cuentecillo, procedente de Ricla, del cura y el monaguillo que no quieren escuchar las acusaciones que se hacen mutuamente, excusándose en que no pueden oírse debido al viento, y que es, por tanto, versión de ATU I777A* «I Can't Hear You».

- Una versión del «Chiste del sermón de la paciencia», procedente de Ricla, versión de ATU I785C The Sexton's Wasp Nest.

- Un chiste de una abuela en el confesionario, procedente de Ricla, versión de ATU I805 Confessions of a Pious Woman.

- Un chiste, procedente también de Ricla, sobre una señora que va a confesarse y que reúne motivos característicos de los tipos ATU I806* Tales of Confessions y ATU I83IA* Inappropiate Actions in Church.

- Una historia de Jaimito - característico protagonista de los chistes-, procedente de Morata de Jalón, y que es una combinación de los tipos ATU I807B Sleeping with God's Daughters y I842A* The Avaricious Clergyman.

- Uno de los frecuentes cuentecillos en los que se parodia un sermón, atribuido aquí a Fermín Pascual, procedente de Ricla, y que es versión de ATU I824 The Sermon Parody, aunque su fórmula final recuerda también a ATU I825A Preaching the Truth y ATU I940 The Extraordinary Names.

- $\quad$ Dos variantes, procedentes respectivamente de Morata de Jalón y Salillas de Jalón, de ATU I83I The Clergyman and Sexton at Mass —referida, la primera, al cura al que regalan dos conejos y, la segunda, al cura de Calatorao-, en las que aparece el característico diálogo en que se parodia la salmodia en latín durante la misa.

- Una anécdota atribuida, también en Ricla, a José «el Chiroba» y que, por la ingeniosa respuesta burlesca dada al cura por su protagonista, podría considerarse una variante de ATU I832* The Boy Answers the Clergyman.

- Un relato, procedente de Morata de Jalón, que contiene motivos de ATU I840 At the Blessing of the Grave, the Clergyman's Ox Breaks Loose y I842A* The Avaricious Clergyman y en la que, de nuevo, se parodia la salmodia en latín, esta vez durante un entierro.

- Una anécdota, procedente de Ricla y atribuida a mosén Pedro, que es aplicación del conocido chiste anticlerical en el que alguien descubre la relación entre el cura y la casera escondiendo en la cama de esta un utensilio del hogar -ATU I842C* The Clergyman's Nights-.

- Un cuento, procedente de Ricla, que, aunque no aparece en los catálogos consultados, podría considerarse una variante de ATU I85I Anecdotes 
about Devout Women - es, en todo caso, un tipo existente en el folklore de Aragón, como demuestra la coincidencia casi exacta de su argumento, incluso del nombre de su protagonista, Gregoria, con el cuento recogido en la comarca de las Cinco Villas por Luis Miguel Bajén y Mario Gros (I994: c-24).

- Una anécdota, procedente de Ricla, conocida como «La liebre del tío Oria», que, por su temática, podría considerarse una variante de ATU I86I Anecdotes about Judges.

- Seis anécdotas atribuidas en Ricla al tío Tereso, todas ellas claramente «cuentos de la cacería» y versiones o variantes de ATU I89oF Shot Causes a Series of Lucky or Unlucky Accidents, ATU I894 A Man Shoots a Ramrod Full of Ducks, ATU I89 I Catching a Rabbit, ATU 1960 The Great Animal Or Great Object y ATU I889C Fruit Tree Grows from Head of Deer - por su gran interés las analizaré posteriormente-.

- Un gran número de versiones de la conocida canción de «Vamos a contar mentiras» -ATU I935 Topsy Turby Land_, extraordinariamente difundida en la comarca. De las diversas versiones recogidas cabe destacar una, procedente de La Almunia de Doña Godina, a la que sus informantes conocían con el significativo título de «Baturradas» y que, al igual que otra de las versiones, procedente de Chodes, coincide en gran medida con el relato n. ${ }^{\circ} 443$ de los recogidos en Castilla y León por Espinosa (hijo) (I996-I997), en la que destaca su carácter escatológico.

- Una anécdota atribuida en La Almunia de Doña Godina a un tañedor de guitarrico y que no es sino un conocido cuentecillo licencioso con doble sentido, en el que la viuda del tañedor lamenta en su funeral que lo entierren con «eso» que lleva entre las piernas y que tanto placer le proporcionaba en vida — se trata de una variante de Boggs (I930) I940*E, que se corresponde de forma bastante fiel con el relato que Oriol y Pujol (2004) catalogan en RondCat como C-OI4-.

Hasta aquí la relación, expuesta de manera sucinta, de los relatos recogidos y analizados y que, como decía en un principio, pueden ser considerados, en razón de su temática y estructura, como cuentos breves de carácter jocoso. El repertorio, sin duda, podría ampliarse sumándole un buen número de anécdotas, dicterios y chistes, en los que sin embargo no me detendré, por tratarse o bien de casos evidentemente reales, o bien, en el caso de los chistes, por presentar argumentos muy alejados de los que se encuentran en los catálogos del cuento folklórico.

En cualquier caso, puede comprobarse cómo, salvo por algunas pocas excepciones, la mayoría de los cuentos jocosos anteriormente expuestos presentan algún tipo de dificultad a la hora de catalogarlos. Así, su clasificación ha tenido que solventarse en demasiadas ocasiones con los socorridos recursos de considerarlos variantes temáticas, híbridos de distintos tipos —en razón de la presencia en ellos de motivos característicos de estos- o versiones de tipos que son en realidad epígrafes de una sección del catálogo aún no desarrollada — como sucede en los casos en que nos encontramos con anécdotas sobre gitanos, beatas o jueces-. Ninguna de estas precarias soluciones debería, sin embargo, resultarnos plenamente satisfactoria si es que realmente queremos llegar a tener un auténtico y exhaustivo catálogo internacional del cuento tipo, por lo que resulta imprescindible, como 
mínimo, una reflexión acerca de esta problemática, que, como todos sabemos, afecta especialmente a los cuentecillos jocosos.

En cualquier caso, la opción de ignorar tales relatos o resignarse a no catalogarlos no parece la más adecuada, pues, como podrá observarse en los apuntes sobre la clasificación de algunos de los ejemplos del listado, en ciertos casos no queda la menor duda de que se corresponden con tipos estables y difundidos en la tradición hispánica, lo que se pone de manifiesto en la coincidencia o fuerte semejanza con propuestas de tipos de los catálogos de Boggs, Robe o Haboucha, de algunos catálogos de ámbito nacional o local o con los argumentos de tipos no incluidos en ATU que se recogen en RondCat. ${ }^{4}$

Esta última opción, la de atribuir al menos un código alternativo a los argumentos de relatos de los que se sospecha existe una tradición estable, defendida por Carme Oriol y nuestro añorado Josep Maria Pujol, resulta muy sensata, siempre y cuando no se acabe convirtiendo en una catalogación alternativa que no lleve a una posterior revisión a medio o largo plazo del catálogo internacional. Así pues, habría que articular un mecanismo o un protocolo que permitiese la inclusión de tales tipos, junto con los propuestos en catálogos de carácter nacional o local, como medio para mejorar paulatinamente el índice internacional. A este respecto, la creación de bases de datos a modo de edición digital, como se ha hecho para el caso del catálogo de la rondallística catalana, podría facilitar notablemente esta labor.

Sea como fuere, esta es una tarea que excede tanto mi capacidad como el espacio del que ahora disponemos. Por ello, para observar en detalle algunos de los problemas sufridos en la catalogación de los relatos anteriormente enumerados, me detendré en un par de casos particulares que considero, por otra parte, especialmente interesantes.

\section{Los cuentos de la cacería}

De entre los cuentecillos jocosos recogidos en la comarca de Valdejalón, resultan especialmente interesantes para el caso que nos ocupa las seis anécdotas atribuidas al tío Tereso y que, como antes apuntaba, son, evidentemente, versiones de los conocidos como «cuentos de la cacería», lo que nos hace pensar en el afamado tío Tereso como el perfecto ejemplo del cazador proverbialmente exagerado, que relata inverosímiles lances de caza. Todas ellas fueron recogidas a un grupo de personas de la localidad de Ricla, donde pervive la fama del tío Tereso, y aparecen en los fonogramas CI-IO5, corte 2; CI-IIO, cortes 7 a IO y I2, y, también —se trata de las mismas grabadas en una segunda ocasión-, en CI-III, cortes 73 a 76.

Las tres primeras — «La liebre del tío Tereso», de la que existen dos versiones (CI-IO5, corte 2, y CI-IIO, corte 7) y las no tituladas que aparecen en el fonograma (CI-IIo, cortes 8 y 9) - no son problemáticas, pues presentan claramente los mismos argumentos de ATU I889C Fruit Tree Grows from Head of Deer — con la única peculiaridad de que los proyectiles utilizados por el tío Tereso son huesos de cereza, de los que uno acaba en los riñones de una liebre, donde luego llegará a

4. Mientras no se consiga culminar la magna obra de catalogación del cuento hispánico realizada por Camarena y Chevalier, considero que debería tomarse en mayor y mejor consideración el catálogo desarrollado en su día por Boggs, que, pese a sus limitaciones, sigue demostrándose válido para la catalogación de los cuentos folklóricos hispánicos. 
crecer un árbol—; ${ }^{5}$ de ATU I89oF Shot Causes a Series of Lucky or Unlucky Accidents - el caso en el que, mientras hacía sus necesidades, mató dos liebres de un mismo tiro-y ATU I894 A Man Shoots a Ramrod Full of Ducks - la ocasión en que cazó una bandada de ánades al ensartarlos a todos por los ojos con la baqueta de su escopeta, pues de nuevo se había quedado sin municiones.

Por el contrario, las dos últimas (CI-IIo, cortes Io y I2) son imposibles de hallar con idéntico argumento en ATU o en el resto de los catálogos consultados. En el primer caso, se trata de la anécdota, muy conocida en la zona, en la que el tío Tereso, tras pasar el día intentando coger caracoles sin conseguirlo, se duerme una siesta en un ribazo y despierta de esta cubierto totalmente de caracoles, hasta el punto de no lograr levantarse por el peso de estos. En el segundo, una historia auténticamente delirante, se nos cuenta —o mejor dicho, se insiste en que el tío Tereso lo contaba- que una vez, bebiendo agua, cogió un «micobrio» y no se le ocurrió otra cosa que meterlo en su cabaña, que tuvo que acabar hundiendo porque creció hasta tal punto que no podía sacarlo de ella.

Como decía antes, una posibilidad, bastante precaria, eso sí, para clasificar la historia sobre los caracoles sería la de considerar que estamos ante una variante local de ATU I89 Catching a Rabbit; no obstante, obviando el hecho de que no se trata de una cacería de conejos, sino de recoger caracoles - lo que quizá sería el menor de los problemas-, y aunque el tipo se propone para formas misceláneas, resulta imposible ajustarse a ninguna de las posibles formas o variantes del análisis que ofrece ATU, que, pese a mostrar la voluntad de reunir en este tipo un buen número de subtipos anteriores, no deja de definirlo en razón de algunos aspectos temáticos.

Por otra parte, la historia del «micobrio», aun formando parte del conjunto de anécdotas del afamado tío Tereso, solo parece clasificable poniéndola en relación con los cuentos de mentiras y exageraciones, pudiendo, como mucho, ser considerada una variante de un tipo también misceláneo, como es ATU i960 The Great Animal Or Great Object. En este caso, sin embargo, nos encontramos de nuevo con que resulta muy diferente de los argumentos típicos de las variantes de este, con el agravante de que en modo alguno se inserta en el marco narrativo de la competición de mentiras en el que suelen aparecer estos relatos - a lo sumo, si considerásemos asimilable el «micobrio» del cuento a un gran invertebrado, podría proponerse la catalogación de esta anécdota como una variante del también misceláneo tipo ATU I960M The Great Insect-.

Basten estos análisis para constatar cómo en un pequeño repertorio de un tipo de cuentos tan conocido y difundido como son los llamados «cuentos de la cacería» nos topamos inmediatamente con problemas de clasificación como los que antes señalaba: la dificultad de «hacer encajar» los argumentos más novedosos $\mathrm{u}$ originales en los tipos que nos ofrecen los catálogos consultados y el recurso continuo a tipos misceláneos, que, sin embargo, no parecen capaces, como queda demostrado, de englobar todas las posibles versiones de estos cuentos, cuya riqueza en variantes parecería estar limitada tan solo por la, por otra parte, desbordante fantasía de los cazadores a los que se atribuyen. Ello me lleva a pensar que, pese al más que loable esfuerzo realizado por Uther en la racionalización del Índice inter-

5. De manera muy significativa, el narrador de la primera versión añade al final de esta, refiriéndose a su protagonista y al caso sucedido, «y aún encima lo contaba por ahí». 
nacional del cuento tipo y pese a que los resultados son, sin la menor duda, dignos de elogio, es necesario todavía, especialmente en los apartados en que la riqueza en variantes es excepcional, simplificar el índice de tipos. Esto podría lograrse poniendo el énfasis en los elementos estructurales de cada tipo —su marco narrativo o planteamiento, principalmente-, dejando en un segundo plano o restando importancia a los elementos que simplemente dan una textura peculiar a las diversas variantes locales, es decir, a los motivos puramente temáticos.

En cualquier caso, como se verá a continuación, la complejidad de los problemas a que nos enfrentamos es tal que lo que aquí parece una buena opción se demuestra totalmente inconveniente para otros tipos de cuentos.

\section{La baraja: máquina de imaginar}

Con este enigmático subtítulo, en el que deliberadamente parafraseo a Jean-Pierre Étienvre - cuyo clásico sobre los márgenes literarios del cuento resulta imprescindible en el terreno en el que ahora me interno (Étienvre I990)—, quiero ahora referirme a un par de relatos recogidos por Carolina Ibor en La Almunia de Doña Godina - las dos versiones de ATU I6I3 Playing Cards are My Calendar and Prayer Book a las que antes me refería- y que aparecen desgajados en cuatro de los fonogramas del trabajo llevado a cabo en Valdejalón, tanto por las dificultades de sus narradores - un matrimonio de esta localidad - para recordarlos y relatarlos sin interrupciones como por la conveniencia de separar los relatos propiamente dichos de los juegos de cartas que les dan sustento y sentido y de la explicación del significado o interpretación que se da a cada uno de los naipes utilizados en ellos.

El primero de los relatos (CI-7I, cortes 66 a 68) es narrado en dos intentos por Enrique Gil, pero con tantas dificultades que resulta algo confuso, por lo que apenas me detendré en él. No obstante, los fragmentos que recuerda —que se corresponden con la interpretación de algunas de las figuras de la barajason suficientes para entender que se trata de una versión de la misma narración que, personalmente, grabé, junto a Javier Lacasta y José Ángel Gracia, de boca de Gregoria López Mansilla en Aguas (Huesca) en I996 (González, Gracia y Lacasta I998: 348-349). El segundo (CI-7I, cortes 70 a 72), narrado y explicado también en dos intentos, era mucho mejor recordado por su narradora, Carmina, quien lo aprendió de su padre, y supone, sin duda, un magnífico ejemplo de este tipo de narraciones, en las que resulta casi imposible separar lo puramente narrativo de su componente lúdico — por lo que quizá sería incluso conveniente definir para ellas un subgénero etnopoético propio-. Lo explico a continuación de manera resumida.

El cuento se relata acompañándose de una serie de naipes de la baraja española, que van depositándose sobre la mesa en determinados momentos de la narración. Esta comienza hablándonos de cuatro caballeros que deciden hacer un alto en el camino para tomar unos vinos en una posada - se sacan entonces del mazo de la baraja los cuatro caballos de la baraja y se disponen sobre la mesa-. La posadera - se extrae ahora la sota de copas del mazo de la baraja- va sirviendo las rondas con las que cada uno de los caballeros invita a sus compañeros hasta que se agota el vino, por lo que se ve obligada a bajar a la bodega a por más. Entre tanto, el caballero que ha invitado a la última ronda sugiere la posibilidad de marcharse sin pagar, lo que definitivamente hacen todos — se introducen de nuevo 
los caballos en el mazo de la baraja-. Cuando la posadera se da cuenta de que los caballeros se han ido sin pagar, se enfurece y decide ir a buscarlos — se hace dar vueltas a la sota de copas alrededor del mazo de cartas-, hasta que, finalmente, los encuentra a los cuatro juntos - lo que se evidencia al cortar la baraja y aparecer, en efecto, los cuatro caballos-.

Como se puede suponer, para que el juego funcione y se logre el efectista final - propio de un auténtico truco de prestidigitador- hay que preparar previamente los naipes y, con suma habilidad y disimulo, introducir dos de los caballos bajo el mazo de cartas y dos sobre él, de manera que al cortar el mazo los cuatro acaben juntos - lo que según su narradora lograba hacer su padre sin que ella y sus hermanos se dieran cuenta, gracias a que la propia narración le servía para distraerlos de los movimientos que hacía con sus manos-.

Si me detengo ahora en este ejemplo híbrido de juego y narración no es por lo pintoresco que pueda resultar o por lo sugerente del procedimiento - que bien pudo inspirar las conocidas obras de Italo Calvino Il Castello dei destini incrociati y La taverna dei destini incrociati-, sino, sobre todo, por los problemas de catalogación -incluso genéricos - surgidos a la hora de analizarlo para el trabajo al que vengo refiriéndome.

Ya en su día, en un artículo publicado en la revista Temas de Antropología Aragonesa (González 2000: I5-38), estudié con detalle este tipo de relatos, junto con algunos juegos y rimas, construidos y explicados a partir de la baraja, analizando varias versiones procedentes de Aragón, Navarra, Álava, Madrid y Valladolid y reflexionando sobre ellas. Por lo que pude observar entonces - haciendo uso todavía de la revisión de Thompson del Índice internacional del cuento tipo-, en nuestro folklore los juegos de naipes que tenían un componente narrativo más evidente - relatos explicados o representados a partir de los naipes - se correspondían perfectamente con dos tipos del catálogo internacional: el I6I3 —el caso del soldado que tiene que utilizar la baraja para rezar, generando un malentendido por el que es juzgado y posteriormente absuelto- y el 2340, el último de los tipos de los cuentos de fórmula, destinado a dar amplia cabida a los relatos explicados a partir de la baraja, y para el que encontré la existencia de al menos dos variantes: una semejante al primero de los testimonios aquí expuesto, que se basa en formar un cuadro con ciertos naipes y ciertas reglas, — siendo el relato la clave para conseguirlo- y otra en el que todos y cada uno de los naipes de la baraja española reciben una interpretación, de manera que al ir sacándolos uno a uno dan como resultado una larga narración.

La actual revisión del catálogo internacional del cuento tipo, a la que no quiero ahorrar elogios, pues ciertamente ha solucionado muchos problemas y ha mejorado notablemente la facilidad de uso y aplicación del índice, ha generado, sin embargo, para el caso que nos ocupa, cierto problema al eliminar el último de los tipos citados e incorporarlo al tipo I6I3. Debido a este cambio, ya no queda más remedio que considerar el relato de Carmina, que antes exponía resumidamente, como una variante del tipo I6I3.

En principio esto no debería resultar demasiado problemático, al tener todos los cuentos a los que me he referido una estructura semejante, en la que la baraja aparece como una suerte de máquina o lenguaje apropiado para narrar, y al alcanzar todos ellos un efectista y sorprendente final gracias al juego que acompasa el relato — de hecho, la fusión de ambos tipos en uno iría en la línea que antes 
proponía de eliminar diferencias temáticas, definiendo fundamentalmente el tipo por sus características estructurales-. Sin embargo, si se presta atención a las características del género que nos ocupa, el cuento jocoso, se convendrá conmigo en que las versiones de los relatos que se ajustarían más al antiguo tipo 2340 no son propiamente cuentos jocosos y en que en ellas el juego, o lo que viene a ser lo mismo, la fórmula, se impone sobre la historia relatada, que, como suele suceder en los cuentos de fórmula, pasa a un segundo plano, cuando no es simplemente una mera excusa o un discurso con escaso sentido. Visto lo visto, quizá hubiera resultado más adecuado en este caso el mantenimiento del tipo 2340 en el índice internacional o bien, como mal menor, la supresión del tipo I6I3, asimilándolo al anterior, lo que quizá resultaría menos problemático en la medida en que los cuentos de fórmula - pese a su problemática relación con el resto de los cuentos folklóricos- se definen más por sus características formales que por sus temas.

En cualquier caso, aunque en términos prácticos no sea demasiado importante el problema observado - pues disponemos de la posibilidad de catalogar estos relatos con ATU-, debe llevar de nuevo a una reflexión sobre los problemas que el concepto de tipo genera al fundamentarse en rasgos temáticos y estructurales a un mismo tiempo y estar definido de una manera no muy rigurosa, excesivamente dependiente, a mi modo de ver, de la idea de tradición.

\section{Referencias bibliográficas}

ANDOlZ CANELA, Rafael (I992): El humor altoaragonés. Zaragoza: Mira Editores.

BAJÉn García, Luis Miguel; Mario Gros Herrero (I994): La tradición oral en las Cinco Villas. Cinco Villas, Valdonsella y Alta Zaragoza. Zaragoza: Diputación de Zaragoza.

BENJAMIN, Walter (I973): «El narrador». Revista de Occidente núm. I29 (I973): 3OI333.

Boggs, Ralph S. (I930): Index of Spanish Folktales. Folklore Fellows' Communications 9o. Helsinki: Suomalainen Tiedeakatemia.

CAMARENA LAUCIRICA, Julio; Maxime Chevalier (I995-2003): Catálogo tipológico del cuento folklórico español. Madrid: Gredos (vols. I y 2, I995-I997). Alcalá de Henares: Centro de Estudios Cervantinos (vols. 3 y 4).

Chevalier, Maxime (200o): «Chascarrillos aragoneses y cuentos folklóricos». Temas de Antropología Aragonesa núm. Io (2000): II-26.

EsPInosA, Aurelio M. (hijo) (I996-I997): Cuentos populares de Castilla y León. Madrid: CSIC.

ÉtienVRe, Jean-Pierre (I990): Márgenes literarios del juego. Una poética del naipe: siglos XVI-XVIII. Londres: Tamesis Books Limited.

GonzÁlez SAnZ, Carlos; José Ángel Gracia PARdo; Javier LACASTA MAZA (I998): La sombra del olvido. Tradición oral en el Pie de Sierra Meridional de Guara. Huesca: Instituto de Estudios Altoaragoneses.

GonzÁlez SANZ, Carlos (I996): Despallerofant. Recopilació i estudi de relats de tradició oral recollits a la comarca del Baix Cinca. Fraga: Institut d'Estudis del Baix Cinca. 
- (2000): «La Sota Tuna. Los naipes como procedimiento de creación literaria y representación del caos». Temas de Antropología Aragonesa núm. 9 (2000): I5-38.

- (20I2): «Cuentos y otros relatos folklóricos». En Carolina IвOR MONESMA: Músicas y palabras en Valdejalón. Zaragoza: Asociación Cultural L’Albada, p. 249275 .

HAвOUCHA, Reginetta (I973): Classification of Judeo-Spanish Folktales. Baltimore: Johns Hopkins University.

Ibor MoneSma, Carolina (20I2): Músicas y palabras en Valdejalón. Zaragoza: Asociación Cultural L'Albada.

RAMos, Rosa Alicia (I988): El cuento folklórico: una aproximación a su estudio. Madrid: Pliegos.

RoвE, Stanley L. (I973): Index of Mexican Folktales. Including Narrative Texts from Mexico, Central America and the Hispanic United States. Folklore Studies núm. 26. Berkeley-Los Ángeles-Londres: University of California Press.

RondCat: cercador de la rondalla catalana. Arxiu de Folklore. Departament de Filologia Catalana de la Universitat Rovira i Virgili. <http://www.sre.urv.cat/rondcat $>$ [fecha de consulta, septiembre de 20I2].

Rubio JimÉnEZ, Jesús (I99I): «La novela de viaje aragonesa (I925-I928): Crisis y contradicciones del costumbrismo aragonés en los años veinte». En Jornadas sobre prensa y sociedad. Logroño: Instituto de Estudios Riojanos, p. II5-I3O.

Thompson, Stith (I96I): The Types of the Folktale. Antti Aarne's Verzeichnis der Märchentypen, Translated and Enlarged by Stith Thompson, (Second Revision). Folklore Fellows' Communications I84. Helsinki: Suomalainen Tiedeakatemia.

UTHER, Hans-Jörg (2004): The Types of International Folktales. A Classification and Bibliography. Based on the System of Antti Aarne and Stith Thompson. Folklore Fellows' Communications 284, 285, 286. Helsinki: Suomalainen Tiedeakatemia. 